\title{
Review of the Application of Nanotechnology for Sustainable Construction Materials
}

\author{
Ayodeji Oke ${ }^{1, a}$, Clinton Aigbavboa ${ }^{1, b}, K_{\text {Kgothatso Semenya }}^{1, c}$ \\ ${ }^{1}$ Department of Construction Management and Quantity Surveying, University of Johannesburg, \\ Doornfontein, 2028, South Africa \\ aemayok@gmail.com, caigbavboa@uj.ac.za, kgothatsosemenya@gmail.com
}

Keywords: Nanotechnology; Sustainable construction; Sustainable development.

\begin{abstract}
The construction industry is one of the major contributors to the economy development of any country, hence, the need to investigate new technological ways that will ensure the growth and development of the industry. Using existing literature materials, the adoption of nanotechnology as a technological method for construction materials were examined. It was observed that the adoption of nanotechnology can aid new building typologies and opportunities for sustainable use of construction materials for the achievement of sustainable developments in architecture, engineering and construction projects.
\end{abstract}

\section{Introduction}

The construction industry can surely be regarded as one of the most important sources of economic growth and direct development, along with the related construction activities. This particular sector has a major role to play towards the economic growth and advancement of a country. This industry generates employment and offers job opportunities to millions of unskilled, semi-skilled and skilled work forces in any nation. It additionally assumes an integral stance in creating salary in both formal and casual segment. The industry further works to supplement remote trade income acquired from the exchange of engineering operations and construction materials [1]. Nanotechnology and its links with ICT have been greatly recognized as the ones to lead a society to a new industrial revolution. And, with regards to the construction industry, nanotechnology offers great opportunities towards developing new materials/components with new and exceeding functionality [2].

Construction industry is a sector that holds great economic importance and relevance dealing with coarse components consumed in large amounts, hence with and exceeding requirement for innovations that would work to mitigate such issues [3]. Nanotechnology has received much attention with direct focus also being directed to the construction industry, because of the industry being a great integrator of solutions offered by other industrial sectors, that is, water supply integrations in buildings, heating, ventilation and communication systems among others [2]. Hence, the need to examine new procedures, material properties and frameworks that will guarantee the persistent development, improvement and sustainable function of the construction industry. This study therefore examine the advantages of nanotechnology for sustainable construction materials, it also assess the economic implications as well as the potential health, environmental and societal impacts of applying nanotechnology to basic construction materials. Table 1 indicate the level of usefulness of nanotechnology in selected construction materials.

\section{Nanotechnology for Concrete}

The construction industry finds concrete along with steel as its cornerstone materials. And, it is estimated that 3.3 billion tons of the binder in concrete, that is, cement, were produced all over the world. This is a just about $8 \%$ expansion from 2009, and overall creation of bond keeps on expanding, impelled by the developing economies, such as China and India [4]. Therefore, concrete 
in particular, has become and is an excellent candidate for nanotechnological manipulations because of its nano-sized structure comprising of cement hydrates, aggregates and additives, which is complicated [2].

Table 1. Level of Usefulness of Nanotechnology for Construction Materials.

\begin{tabular}{|l|c|l|l|l|l|}
\hline & Very high & High & Average & Low & Very low or none \\
\hline Concrete & $\mathrm{x}$ & & & & \\
\hline Structural steel & $\mathrm{x}$ & & & & \\
\hline Glass & & $\mathrm{x}$ & & & \\
\hline Timber & $\mathrm{x}$ & & & & \\
\hline Coatings & & $\mathrm{x}$ & & & \\
\hline
\end{tabular}

The properties of the components and hydrate of concrete at the nanoscale strongly influence concrete itself as a macro-material [5], meaning that its properties are strongly influenced by C-S-H (calcium silicate hydrates) gel, which is a nanosized composite material that is a variable, and significantly modified by a multi-scale network of capillary pores and microcracks [3]. Furthermore, concrete is the most omnipresent man-made materials in construction [6, 7], which is nano-structured (at related scales), and consists of many phases, that ages over time. The properties of concrete exist in, and the degradation mechanisms occur across, multiple length scales (nano to micro to macro) where the properties of each scale derive from those of the next smaller scale [7]. Understanding the structure at nano-level impacts the imperative procedures identified with creation and utilization of construction materials [6] - quality advancement, crack, erosion - and even tailor the coveted properties. For example, the development of materials with new properties that will usher in the ability for those materials to self-clean, to resist the issue of discoloration, protection against graffiti, high scratch and wear resistance, has become really important for a vast number of application in construction.

The properties of concrete can be adjusted in such a large number of courses, one of the most ideal ways is the fuse of nano particles. Nano particles in terms of nano silica, nano clays, nano titanium Oxide (TiO2), Nano Iron (Fe2 O3), Nano alumina (A12 O3), Copper Oxide (Cuo), Zinc Peroxide $(\mathrm{ZnO} 2)$ and $(\mathrm{ZrO} 2)$ Zirconium dioxide [5]. In emphasis, Sobolev et al. (2008) states that composites can be nano-built by the fusion of nano-sized building pieces or protests (e.g., nanoparticles and nanofibers) to control material behavior and include novel properties, or by the uniting of atoms onto cement particles, aggregates, added substances (counting nano-sized added substances) to give surface functionality, which can be changed in accordance with advance particular interfacial cooperation. Within the last decades, the performance of concrete has been essentially enhanced by applying various types of miniaturized scale and nanoparticles and/or by the utilization of expository techniques considering seeing at the nanoscale [8].

The mixture of cement, sand, aggregates and water may be viewed as a simple definition of what modern concrete is, but it is more than simple. Today, more is requested from concrete than any other time in recent memory as it is being utilized as a part of various structures and exceptional applications such as high performance (HPC), self-levelling concrete (SLC), self-compacting concrete (SCC), ultra-high performance concrete (UHPC) etc. [5]. A smart material such as self-healing concrete [9] is one of the most capable under development by the scientific construction materials institutions worldwide. Furthermore, these very high demand advancements require the utilization of compound admixtures with a specific end goal to alter/ control at least one properties of the fresh or hardened properties of cement. However, the most utilized admixtures as a part of bond and cement incorporate quickening agents, set retarders, air entraining operators, super-plasticizers and others [5]].

\section{Nanotechnology for Structural Steel}

Nanotubes form part of one of the most interesting group of nanomaterials [10] and it is created as single-walled tubes in constrained amounts or as blends of multi-walled tubes. Carbon nanotubes 
consist of diameters of 1-10 nm and are efficiently made out of graphite as long thin. Steel is a hundred times weaker than carbon nanotubes [11] and only one divided by six of the weight with direct regard to its ability in thermal and electrical conductivities. Furthermore, a carbon nanotube composite has recently been reported to be six times stronger than conventional carbon fiber composites. Their potential applications vary but can be utilized in sensors, high strength composites, field emission devices for displays and creating storages of hydrogen [3]. The practical relevance of metals can be seen everywhere, from aluminum, steel and titanium utilized in infrastructure and transportation to shape-memory alloys for biomedical implants and carriers for cancer detection and treatment utilizing metal nanoparticle. Though many would only realize the importance of these at macro-scale with regard to their applications, creating and improving the properties for which they are known requires control at the nano-scale [12].

Steel is one of the most vital and indispensable material in construction activity [13], and it is a versatile material of technological importance with its outstanding recyclability and ease of manufacturing greatly contributing to eco-efficient construction [14]. In spite of the fact that steel is great in strain it has an issue with fatigue. Fatigue is a noteworthy issue prompts the disappointment when it is subjected to cyclic loading. Subsequently, the fatigue of the steel will be decreased by including copper nano particles. At the point when copper nano particles are added to the steel, the surface of the completed steel becomes smooth and even. Therefore, this equity of the surface may lessen the stress, henceforth the steel may have less stress risers and fatigue breaking is likewise constrained. New era steel is additionally created with higher corrosion resistance. New stainless steel is additionally created and will be reasonable in light weight structures and inflexible/rigid bridges [13]. Examples of such steel developments include Sandvik NanoflexTM, a new generation stainless steel developed by Sandvik Nanoflex Materials Technology. Due to its high performance, it is suitable for application which requires lightweight and rigid designs. Its good corrosion, formability and wear resistance can keep life-cycle costs low [11].

Advancement in ferrous metallurgy has been portrayed fundamentally by the improvement of nanotechnologies [15], specifically, the generation of amazing materials utilized as a part of hardware, optics, development, the power business, assembling, astronautics, and somewhere else.

\section{Nanotechnology for Glass Materials}

Nanoscale science and engineering, or "nanotechnology" as it is usually known, has been a basic segment of glass innovation for years. Furthermore, cutting edge utilizations of glass in such assorted fields as energy, medicine, gadgets/electronics, photonics, and communication are fundamentally subject to our mindfulness and appreciation about the inborn associations amongst glass and nanotechnology [16].

In the course of recent years, item development in the glass itself has concentrated on meeting an extending scope of functionalities. These incorporate creating glass with enhanced execution as far as warm protection, solar control (to decrease heat misfortune and manage ventilation), security and safety, imperviousness to fire, the reduction of noise, against reflection, self-cleaning, hostile to scratching, and visual appearance [17]. Incorporating nano-materials in to glass matrices allows for the production of windows with the capability to control how light and heat pass through building walls [18]. And that these applications may bring about an increment in energy efficiency by conserving building heat energy through a reduction of heat loss, for example, utilizing nano-manufactured low emissivity glass, and reducing energy consumption for ventilation and air-conditioning by restricting solar heat through the usage of solar control and heat absorbing glass. Nanotechnology has been utilized for a long time in the application and production of coatings created to offer features for improved glass performance [17], stemming through trial and error before the emergence of the recent attention given to nanotechnology.

\section{Nanotechnology for Timber}

Utilizing nanotechnology within the forest products industry could give rise or bring about 
previously unimagined growth and advancement opportunities for bio-based products. Nanotechnology will bring about a one of a kind up and coming era of wood-based items that have hyper-performance and predominant serviceability when used in severe environments. Furthermore, they will have quality properties now just observed with carbon-based composites materials, and they will be both tough while in administration and biodegradable after their useable administration life [19]. Wood is an essential building material; it is a lightweight material simple to process and repair, and it is generally accessible to the construction industry. In addition, wood is conceivably a carbon dioxide unbiased material if delivered, such that, it takes up as much carbon dioxide amid development as it discharges amid rot or burning. Besides, the generation of wood likewise requires generally little vitality for ranger service and wood handling, it can be characterized as a 'low vitality building material [20].

Wood and wood-based materials are going up against extended contention from alternative non-wood materials, for instance, strong, glass, polyvinyl chloride (PVC), aluminum, and steel furthermore composites of various materials. This restriction with various materials has been an essential driver behind late headways in wood-based-and wood-plastic-composites [19].

Expanding the accentuation on wood as a building material could have noteworthy ramifications for worldwide vitality prerequisites and worldwide carbon dioxide discharges [21], so its improvement through nanotechnology offers clearly defined economic, environmental and sustainability benefits, with regards to its usages in the South African construction industry. Other potential advantages will be enhanced conventional wood- and bio-composite items like those now utilized as a part of construction, however with altogether enhanced performance or economy. Nanotechnology will likewise advance the improvement of shrewd wood and biocomposite items and products with a variety of nanosensors built in, to measure forces, loads, moisture levels, temperature, pressure, and chemical emissions [19].

\section{Nanotechnology in Coatings}

Generally, coatings are used as barriers for protection against chemical attacks, abrasion, hydro-thermal differences and for the improvement of aesthetics. With most coatings being in the micro-meter range, nanotechnology is being utilized to develop thick coatings at the nano-meter scale with significant levels of durability and less heat generation due to lower friction. Furthermore, coatings with self-healing and self-cleaning capabilities may be developed [22]. Nano-modified coatings are anticipated to bring in novel functionalities on constructed surfaced and develop long existing construction materials with desired resistant and protective surfaces, furthermore the use of nano-materials for thermal insulation will lead to proper heat management reducing carbon emissions and energy conservation [18]. These coatings may also provide resistance to corrosion, fire retardation and may serve as water repellents which will protect construction materials from contamination, weathering, aging and ultimately aiding their long term serviceability [23].

\section{Conclusion and Recommendation}

The potential advantages and impacts of nanotechnological applications in the construction industry are vast, and such applications represent the link of materials science and engineering towards enhancing the innovative capacity of the industry. The most significant advantage of applying nanotechnology to traditional construction materials is the fact that such materials can be modelled with desired properties that would modify their related functionality, which will help in achieving sustainable construction practice. More so, the economic implications of applying nanotechnology to traditional construction materials is that cheap and accessible infrastructural developments will be achieved through the reduction of material productions costs. In view of this, the applications of nanotechnology should be considered by construction stakeholders including contractors, clients, consultants as well as agencies concerned with monitoring, managing and regulation of construction activities in the quest for the continuous growth and advancement of the construction industry. 


\section{References}

[1] H. A. Ahmadu, Y. M. Ibrahim, A. D. Ibrahim, M. Abdullahi, Modelling building construction durations, J. Fin. Mgt. Prop. Constr. 20(1) (2015) 65-84.

[2] H. Péro, From Nanotechnology to new production systems: the EU Perspective, Nanotechnology in Construction, Special Edition No. 292, Scotland, Springer, 2004.

[3] W. Zhu, P. J. M. Bartos, A. Porro, Application of nanotechnology in construction - Summary of a state-of-the-art report, Mater. Struct. 37(273) (2004) 649-658.

[4] H. G. Van Oss, Reducing cement's CO 2 footprint. Private Sector \& Development, (2011), 10.

[5] J. J. Beaudoin, L. Raki, R. A. Alizadeh, 29 Si MAS NMR study of modified C-S-H nanostructures. Cem. Concr. Comp. 31(8) (2009) 585-590.

[6] K. Sobolev, Z. Lin, I. Flores Vivian, R. Pradoto, Nano Engineered Cements with Enhanced Mechanical Performance. J. Am. Ceram. Soc. 99(2) (2016) 564-572.

[7] F. Sanchez, K. Sobolev, Nanotechnology in concrete - A review, Constr. Build. Mater. 24(11) (2010) 2060-2071.

[8] M. Schmidt, K. Amrhein, T. Braun, C. Glotzbach, S. Kamaruddin, R. Tänzer, Nanotechnological improvement of structural materials-impact on material performance and structural design. Cem. Concr. Comp. 36 (2013) 3-7.

[9] A. Guerrero, J. L. G. Calvo, P. Carballosa, G. Perez, V. R. Allegro, E. Erkizia, J. J. Gaitero, An Innovative Self-Healing System in Ultra-high Strength Concrete Under Freeze-Thaw Cycles. Nanotech. Constr. (2015), pp. 357-362.

[10] P. Holister, J. W. Weener, C. Román, T. Harper, Nanoparticles. Technology White Papers, 3 (2003) 1-11.

[11] V. K. Ganesh, Nanotechnology in Civil Engineering. European Sci. J. 8(27) (2012) 96-109.

[12] C. A. Handwerker, T. M. Pollock, Emerging science and research opportunities for metals and metallic nanostructures. J. Met. 66(7) (2014) 1321-1341.

[13] N. V. Rao, M. Rajasekhar, K. Vijayalakshmi, M. Vamshykrishna, The future of civil engineering with the influence and impact of nanotechnology on properties of materials, Proc. Mater. Sci. 10 (2015) 111-115.

[14] A. R. Flint, B. Smith, M. J. Baker, W. Manners, D. W. Smith, F. M. Burdekin, J. B. Dwight, The design of steel bridges., 1981.

[15] S. V. Kolpakov, V. A. Parshin, A. N. Chekhovoi, Nanotechnology in the metallurgy of steel. Steel Translat. 37(8) (2007) 716-721.

[16] J. C. Mauro, A. J. Ellison, L. D. Pye, Glass: The nanotechnology connection. International J. Appl. Glass Sci. 4(2) (2013) 64-75.

[17] M. M. Andersen, Silent innovation: corporate strategizing in early nanotechnology evolution. J. Tech. Transf. 36(6) (2011) 680-696.

[18] J. Lee, S. Lee, E. Chung, V. C. Reyes, S. Mahendra, Nanomaterials in Civil Engineering. In Springer Handbook of Nanomaterials, (2013), pp. 1039-1062.

[19] T. H. Wegner, J. E. Winandy, M. A. Ritter, Nanotechnology opportunities in residential and non-residential construction. In 2nd International Symposium on Nanotechnology in Construction, Bilbao, Spain, 2005.

[20] T. Goverse, M. P. Hekkert, P. Groenewegen, E. Worrell, R. E. Smits, Wood innovation in the 
residential construction sector; opportunities and constraints. Res. Conserv. Recycl. 34(1) (2001) 53-74.

[21] A. H. Buchanan, S. B. Levine, Wood-based building materials and atmospheric carbon emissions. Envir. Sci. Policy, 2(6) (1999) 427-437.

[22] P. Balaguru, K. Chong, Nanotechnology and concrete: research opportunities. Proceedings of ACI Session on Nanotechnology of Concrete: Recent Developments and Future Perspectives, 2006.

[23] V. S. Saji, J. Thomas, Nanomaterials for corrosion control. Curr. Sci. 92(1) (2007) 51-55. 